\title{
Technical efficiency estimation of dairy farming in Kosovo
}

\author{
Arben Musliu*, Blend Frangu**, Jennie S. Popp ${ }^{\star \star}$, Michael Thomsen ${ }^{\star \star}$, \\ NATHAN KemPER $* *$
}

DOI: $10.30682 / \mathrm{nm} 1903 \mathrm{f}$

JEL codes: Q16

\begin{abstract}
The aim of this research paper is to assess the technical efficiency (TE) of milk production in Kosovo using the stochastic frontier analysis. Research data are collected through surveys from 100 commercially oriented dairy farmers. The study finds that TE of milk production by most of these farms is high. Using the Cobb-Douglas production function, individual measures of TE range from 0.87 to 0.98 (on a scale of 0 to 1.00) with the average being 0.95. There were 57 farms with TE greater than 0.95 and 35 farms with TE less than 0.95. In the study's sample, female dairy farmers have roughly the same mean TE of 0.95 as male dairy farmers. The variation in milk production among the sampled farms was modeled in terms of concentrate and forage feed costs and pre-production costs. The study suggests that concentrate feed and pre-production costs can significantly influence TE of milk production among Kosovar dairy farms.
\end{abstract}

Keywords: Stochastic frontier analysis, Technical efficiency, Milk production, Kosovo.

\section{Introduction}

Increasing global competition is of concern for many small food producers in developing countries. Kosovo is one example. The country has low production levels and marketing systems that are not yet fully developed and lack the capacity to realize production efficiencies (Musliu et al., 2015). Conversely, increasing agricultural production can lead to economic growth (Yuya and Daba, 2018). The common agricultural policy (CAP) in Europe can support the competitiveness of the agriculture sector for the European Union (EU) countries (Signorello and Pappaalardo, 2003; D'amico et al., 2013). Supporting farmers to improve agricultural productivity is another CAP's objective. Kosovo as an aspiring EU country candidate strategically invests in sectors that make agriculture production more efficient and in those that bring gender balance. However, the importation of dairy products remains high despite progress achieved in recent years, which targeted a substitution of domestic dairy products for imported ones. There remains a clear dependence on agricultural product imports (Zuzaku, 2014), which often affects farmers' efficiency (Sauer et al., 2012).

\footnotetext{
* Department of Agricultural Economics, Faculty of Agriculture and Veterinary, University of Prishtina "Hasan Prishtina", Pristina, Kosovo.

** Department of Agricultural Economics and Agribusiness, University of Arkansas, Fayetteville, USA.

Corresponding author: blendfrangu1@gmail.com
} 
Today the local dairy industry covers more than $50 \%$ of the total market share for processed dairy products which is more than 40 million euros (annually). According to the Ministry of Agriculture, Forestry and Rural Development in Kosovo (MAFRD, 2017), there are 136,783 dairy cows that represent $52 \%$ of the total number of bovine animals with a total milk production of 285 thousand tons. Nevertheless, the Kosovo dairy industry is facing diverse challenges (in addition to imports) that may inhibit its growth. The main challenges facing the industry range from poor milk quality, low productivity and efficiency (Bajrami et al., 2017) to gender imbalance in dairy farming. One source of low milk production efficiency in Kosovo can be attributed to the disproportionate use of feed materials. For example, forage and concentrated feed costs often remain high among Kosovar dairy farms. It has been found that these feed costs occupy $57 \%$ of the total production costs and that roughly $61 \%$ of the variation in milk production may be explained from changes in forage and concentrate feeds (Aktürk et al., 2010). Investigating feed costs can be vital when considering efficiency in milk production. Overcoming these challenges may also help the government achieve its goals and generate sustainable profits for producers. Kosovar dairy farms may have a great potential to increase production and displace additional imported dairy products.

The next five years present a growth opportunity for the Kosovo dairy industry to substitute imported dairy products and to increase its presence in regional markets. Both female and male dairy farmers have several opportunities. These opportunities range from being able to boost farm competitiveness to yielding higher milk quantities. Nevertheless, to utilize these opportunities there needs to be improvement in the efficiency of producing milk. Developing an understanding of inputs that influence production efficiency among dairy farms is critical. This can provide farmers with information to select management strategies that could improve efficiency in milk production. However, challenges continue to prevail in achieving complete efficiency in milk production.
Dairy farmers often complain about difficulties pertaining to milk production. This could be in part due to low levels of expertise in milk production and pasture. Small-scale dairy farmers often deliver their milk to milk collection centres, while larger-scale farms (i.e. ranging from 15 to 35 dairy cows) work directly with dairy plant facilities (Musliu et al., 2017). Increasing production requires an efficient utilization of resources (inputs) coupled with stable milk yields. With the help of the government and local dairy associations, it is possible to achieve efficiency in milk production. While central eastern and southern European countries (Slovenia, Croatia, Serbia and Hungary) may have already adopted efficient production systems.

A review of the literature identifies studies that have examined economic aspects of the dairy sector in Kosovo (Musliu et al., 2009; Miftari et al., 2010). However, few reports and studies have looked at the efficiency of milk production while considering feed materials in Kosovo. For example, one study found that the mean technical efficiency (TE) of Kosovar dairy farms was estimated at 0.72 (on a scale of 0 to 1.00 ) with the potential to increase further technical efficiency (Bajrami et al., 2017). In the same study it was recommended for the government of Kosovo to improve their dairy policy. Thereafter, there may have been potential changes in the dairy sector that have led to more efficient milk production. Using the stochastic frontier analysis (SFA) Cobb-Douglas and translog specifications, we investigate levels of efficiency in milk production among Kosovar dairy farms. Unlike other studies that have examined technical efficiency while combining subsistence (non-commercial) and commercially oriented farmers, we focus only in the group of commercially oriented farmers.

\section{Materials and Methods}

\subsection{Data}

Kosovo is in the process of digitalizing and making agricultural data available to the research community. The cross-sectional data for the study were obtained from surveys complet- 
Table 1 - Descriptive statistics of the variables.

\begin{tabular}{|l|c|c|c|c|c|c|c|}
\hline Variables $(x)$ & Unit & $N$ & Mean & St. Dev. & $25^{\text {th }}$ PCTL & Median & $75^{\text {th }}$ PCTL \\
\hline Independent variables & & & & & & & \\
Concentrate feed costs & euro & 92 & 8,404 & 6,157 & 4,441 & 7,352 & 10,889 \\
Forage feed costs & euro & 92 & 7,622 & 5,277 & 4,099 & 6,799 & 9,885 \\
Pre-production costs & euro & 92 & 2,385 & 1,761 & & & \\
\hline Dependent variable & & & & & & & \\
Total milk production & litres & 92 & 67,610 & 49,801 & 30,312 & 59,275 & 87,942 \\
\hline
\end{tabular}

$N$ : number of observations; PCTL: percentile.

ed by female and male commercially oriented dairy farmers throughout Kosovo from June 2017 to September 2017. The objective of the survey was to develop an understanding of the efficiency in milk production among these farmers. There were three steps included in gathering data from the field: (a) choose regions with a large number of dairy farmers; (b) interview farmers; and (c) assess the data for quality and outlying values. The original sample included 100 dairy farms. After addressing data outlying values, the final sample consisted of 92 dairy farms. According to the Agriculture and Rural Development Plan 2007-2013 (ARDP, 2006), MAFRD dairy farms in Kosovo are classified as subsistence, semi-commercial and commercial. From a total of 83,289 dairy farms in Kosovo, there are roughly $1 \%$ or 787 commercial dairy farms (ARDP, 2006). The data collection process targeted only the group of commercially oriented dairy farmers. These farmers are actively participating in the dairy industry, and they work closely with the dairy processors.

\subsection{Descriptive statistics}

Summary statistics for the variables used for analysis are presented in Table 1. The concentrate and forage feed costs are costs incurred during the feeding process. The forage feed costs consist of grass, alfalfa hay, and corn silage costs. Relatedly, pre-production costs consist of dairy cow replacement costs, dairy farm equipment depreciation and maintenance costs and costs of veterinary interventions. These costs occur prior to milk production. The concentrate and forage feed and pre-production costs have means of
$8,404,7,622$, and 2,385 euros, respectively. This suggests that dairy farmers spend significantly more to cover feed than pre-production costs. Due to lower prices in neighbouring countries, most of the grains for the concentrated feeds are imported rather than produced in the country. This may dictate as why farmers appear to spend more on concentrated feeds. The average of total milk production per farm is 67,610 litres and its standard deviation of 49,801 can indicate that there is variability in total milk production. Comparatively, the average annual milk yield per cow is $4,502 \mathrm{~kg}$ (litres) in Serbia including Holstein Friesian and Simmental cattle farms (Pandurević et al., 2015). Among Serbian dairy farms, there are only $15 \%$ of them that have 15 to 30 cows (Bogdanoviü and Petroviü, 2014). Thus, it may be inferred that a Serbian farm having 15 to 30 cows can produce a low of 67,530 and a high of 135,060 litres of milk. In Kosovo, farms with a number of dairy cows greater than 15 appear to be more efficient (Bajrami et al., 2017). From our sample, dairy farms in the $25^{\text {th }}$ and $75^{\text {th }}$ percentiles can produce a low of 30,312 to a high of 87,942 litres of milk, respectively. This depends, however, on the number of dairy cows per farm.

\subsection{Methods}

Stochastic frontier analysis (SFA) is a parametric approach pioneered by Aigner, Lovell and Schmidt (1977) and Meeusen and Van Den Broeck (1977). This method can separate random (statistical) noise from technical efficiency scores and it can obtain estimates of interest from the specified function (Scippacercola and Sepe, 
2016). It is possible to quantify levels of efficiency in milk production using also data envelopment analysis (DEA) as a non-parametric approach. This method was developed by Charnes, Cooper, and Rhodes (1978). One distinction of DEA is that it is less influenced by the specification error than SFA (Reinhard, Lovell and Thijssen, 2000). However, an important and undesirable feature of DEA includes its sensitivity to outlier and missing data values involving the decision making units (DMUs). This can change DMUs' relative efficiency values (Kao and Liu, 2000), where DMUs would correspond to the Kosovar dairy farms. Relatedly, SFA may not be as susceptible as DEA to data outlying values.

Based on the literature and Kosovo's dairy farming context, we use SFA to investigate efficiency in milk production. Specifying the production function is a requirement when using SFA. In this study, the Cobb-Douglas and the translog production functions were used to analyze the data. The translog is more flexible by allowing for alternating scale (Zhang and Kang, 2015), whereas the Cobb-Douglas function is a special case of the translog specification. We use both models to conduct the analysis. First, we use the Cobb-Douglas production function specified as follows.

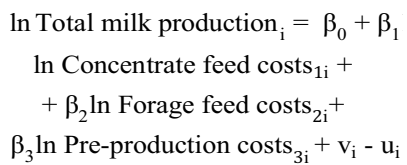

From equation (1), ln denotes the natural logarithm and $\beta_{1}, \beta_{2}$ and $\beta_{3}$ are parameters to be estimated. Total milk production is the dependent variable. The independent variables are concentrate and forage feed costs that indicate costs incurred in the feeding process and pre-production costs that denote costs incurred prior to producing milk. The $\mathrm{v}_{\mathrm{i}}$ term is random error that comes from the statistical noise, and factors that may be outside the control of the dairy farmers in Kosovo. From the model, $u_{i}$ is the inefficiency in the production of milk. In fact, when we have $\mathrm{K}$ dairy farms, efficiency of a dairy farm $\mathrm{k}$ can be evaluated as follows.
Efficiency $_{\mathrm{k}}=\mathrm{e}^{-\mathrm{u}_{\mathrm{k}}}$

Calculating $\hat{u}_{k}$ of $u_{k}$ depends on the distribution of $u_{k}$ and that is influenced by the selected estimation method (Kumbhakar and Lovell, 2000; Pilyavskyy et al., 2012). In addition to equation (1), we consider the translog production function. This differs in that it contains squared and interaction terms for the independent variables. We used $\mathrm{R}$, the programming language and software, to conduct the statistical analyses.

$$
\begin{aligned}
& \text { In Total milk production }{ }_{\mathrm{i}}=\beta_{0}+\beta_{1} \text { ln Concentrate feed costs }{ }_{1 \mathrm{i}}+ \\
& \beta_{2} \ln \text { Forage feed } \text { costs }_{2 \mathrm{i}}{ }^{+} \\
& +\beta_{3} \ln \text { Pre-production } \text { costs }_{3 \mathrm{i}}+0.5 \beta_{11} \\
& \left(\text { ln Concentrate feed costs }{ }_{1 \mathrm{i}}\right)^{2}+ \\
& +\beta_{12}\left(\text { ln Concentrate feed costs }{ }_{1 \mathrm{i}} \ln \text { Forage feed } \operatorname{costs}_{2 \mathrm{i}}\right)+ \\
& +\beta_{13}\left(\text { ln Concentrate feed costs }{ }_{1 \mathrm{i}} \ln \text { Pre-production costs }{ }_{3 \mathrm{i}}\right)+ \\
& +0.5 \beta_{22}\left(\ln \text { Forage feed } \operatorname{costs}_{2 \mathrm{i}}\right)^{2}+ \\
& +\beta_{23}\left(\ln \text { Forage feed costs }{ }_{2 \mathrm{i}} \ln \text { Pre-production costs }{ }_{3 \mathrm{i}}\right)+ \\
& +0.5 \beta_{33}\left(\ln \text { Pre-production } \operatorname{costs}_{3 \mathrm{i}}\right)^{2}+\mathrm{v}_{\mathrm{i}}-\mathrm{u}_{\mathrm{i}}
\end{aligned}
$$

Choosing the desired production functional form, Cobb-Douglas or translog, requires conducting a log likelihood ratio (LR) test. The specifics of this test have been discussed previously (Battese and Coelli, 1995; Coelli et al., 2005). This test is used to determine whether the Cobb-Douglas or the translog function specification is more representative in explaining total milk production in Kosovo. The LR test tests the null hypothesis of the Cobb-Douglas function against the alternative translog specification as presented in equations (1) and (3).

\section{Results and Discussion}

Based on the LR test with a chi-square (Chisq) value of 2.84, the null hypothesis with a log-likelihood of 127.45 is not rejected $(\operatorname{Pr}(>$ Chisq $)=$ 0.83 ) in favor of the alternative with a log-likelihood of 128.87. Therefore, we analyze results pertaining to the Cobb-Douglas production function. This function is useful and has already wide applications in agriculture (Aneani et al., 2011). Although the Cobb-Douglas production function does not permit interaction among inputs as in equation (3), yet this function has 
Table 2 - Stochastic production frontier results.

\begin{tabular}{|c|c|c|c|c|c|c|c|c|}
\hline \multicolumn{9}{|c|}{ Cobb-Douglas production function ( $N=92)$} \\
\hline & \multicolumn{4}{|c|}{ Ordinary least squares estimates } & \multicolumn{4}{|c|}{ Maximum likelihood estimates } \\
\hline Variables and parameters & Estimate & $\begin{array}{l}\text { Std. } \\
\text { Error }\end{array}$ & $\begin{array}{c}t \\
\text { value }\end{array}$ & $\operatorname{Pr}(>|t|)$ & Estimate & $\begin{array}{c}\text { Std. } \\
\text { Error }\end{array}$ & $\begin{array}{c}z \\
\text { value }\end{array}$ & $\operatorname{Pr}(>|z|)$ \\
\hline Constant $\left(\beta_{0}\right)$ & 1.46 & 0.11 & 13.72 & $<0.00$ & 1.49 & 0.11 & 14.15 & $<0.00$ \\
\hline Concentrate feed costs $\left(\beta_{1}\right)$ & 0.44 & 0.21 & 2.09 & 0.04 & 0.48 & 0.21 & 2.30 & 0.02 \\
\hline Forage feed costs $\left(\beta_{2}\right)$ & 0.45 & 0.23 & 1.96 & 0.05 & 0.42 & 0.22 & 1.87 & 0.06 \\
\hline Pre-production costs $\left(\beta_{3}\right)$ & 0.21 & 0.03 & 8.01 & $<0.00$ & 0.21 & 0.03 & 7.87 & $<0.00$ \\
\hline \multicolumn{9}{|l|}{ Variance parameters } \\
\hline Sigma squared $\left(\sigma^{2}\right)$ & 0.00 & & & & 0.01 & 0.00 & 2.62 & 0.01 \\
\hline $\operatorname{Gamma}(\gamma)$ & & & & & 0.64 & 0.30 & 2.17 & 0.03 \\
\hline
\end{tabular}

$N$ : number of observations.

traditionally been used as a production function approach in agriculture (Lyu et al., 1984). Additionally, this function allowed us to examine if there are increasing, decreasing or constant returns to scale among dairy farms. The variance parameters sigma squared $\left(\sigma^{2}\right)$ and gamma $(\gamma)$ were significant at the $5 \%$ level. It was useful also to compare the ordinary least squares (OLS) and maximum likelihood estimation (MLE) estimates of the production function for Kosovar dairy farms. The value added of the OLS to our analysis lies in the possibility to compare these estimates with those of the MLE.

The OLS and MLE estimates of the stochastic production parameters for the Cobb-Douglas model (Table 2) suggest differences in milk production. The variance parameters reveal that $\sigma^{2}$ significant at the 5\% level may indicate a good fit of the model. While $\gamma$ with the same statistical significance level could show that 0.64 (64\%) of the deviation from the total milk production was due to inefficiency effects. Given that both $\sigma^{2}$ and $\gamma$ are significant, it is more useful to closely examine the MLE estimates. The estimates suggest that concentrate feed and pre-pro- duction costs are factors influencing total milk production in Kosovo. For example, concentrate feed costs (OLS $\beta_{1}=0.44$; MLE $\beta_{1}=0.48$ ) and pre-production costs (OLS $\beta_{3}=0.21$; MLE $\beta_{3}=0.21$ ) have positive coefficients indicating that an increase in the use of these factors can increase total milk production. The estimate forage feed costs has also a positive impact (OLS $\beta_{2}=0.45$; MLE $\beta_{2}=0.42$ ) on total milk production. However, it is only close to a marginally significant level (OLS p-value $=0.05$; MLE $\mathrm{p}$-value $=0.06$ ). Variables that are in logarithmic form can be interpreted as estimated elasticities. The sum of the three coefficients on inputs exceeds $1\left(\beta_{1}+\beta_{2}+\beta_{3}=1.11\right)$, which indicates Kosovo dairy farms from our sample face increasing returns to scale. For example, a $100 \%$ increase in all factor levels will result in a $111 \%$ increase in total milk production.

All technical efficiency (TE) scores presented in this study are on a scale of 0 to 1.00 with a score of 1.00 indicating that the farm is $100 \%$ technically efficient in milk production, relative to other farms in the sample. Table 3 provides descriptive statistics for the overall estimated

Table 3 - Technical efficiency scores of dairy farms.

\begin{tabular}{|l|c|c|c|c|c|c|c|}
\hline Production function & Minimum & Mean & St. Dev. & $25^{\text {th }}$ PCTL & Median & $75^{\text {th }}$ PCTL & Maximum \\
\hline Cobb-Douglas $(N=92)$ & 0.87 & 0.95 & 0.02 & 0.94 & 0.95 & 0.96 & 0.98 \\
\hline Efficiency & 0.94
\end{tabular}

N: number of observations; PCTL: percentile. 
TE scores. Using the Cobb-Douglas production function, the average TE of Kosovar dairy farms is 0.95 , while individual measures of TE for these farms range from 0.87 to 0.98 . There are dairy farms in the $25^{\text {th }}$ percentile that have a TE of 0.94 , and those in the $75^{\text {th }}$ percentile with a better TE of 0.96 relative to the rest of the sample.

The number of dairy cows increased by $1 \%$ in Kosovo from 2015 to 2016. In 2015, there were 135,801 dairy cows compared to 136,783 dairy cows in 2016 (MAFRD, 2017). Relatedly, there were only 134,393 dairy cows in 2014 (MAFRD, 2015). Although the increase may not appear sufficiently high, it is of interest to examine its impact in efficiency of total milk production. In this study, the majority of farmers can become technically efficient through progressing from a mean TE of 0.95 to 1.00 . The density of TE scores shows that most dairy farmers are likely to be positioned toward high TE. This suggests that when producing milk, Kosovar dairy farmers seem to be considering adequately the concentrate and forage feed and pre-production costs. There are 57 farms with an efficiency level greater than 0.95 , which may be targeting the maximum of TE in total milk production (Figure 1). Nevertheless, there are 35 farms with an efficiency level less than 0.95 . Achieving gradual efficiency in milk production can be encouraging for Kosovo, which aspires to join the EU. Becoming an EU mem-

Figure 1 - Technical efficiency scores' density.

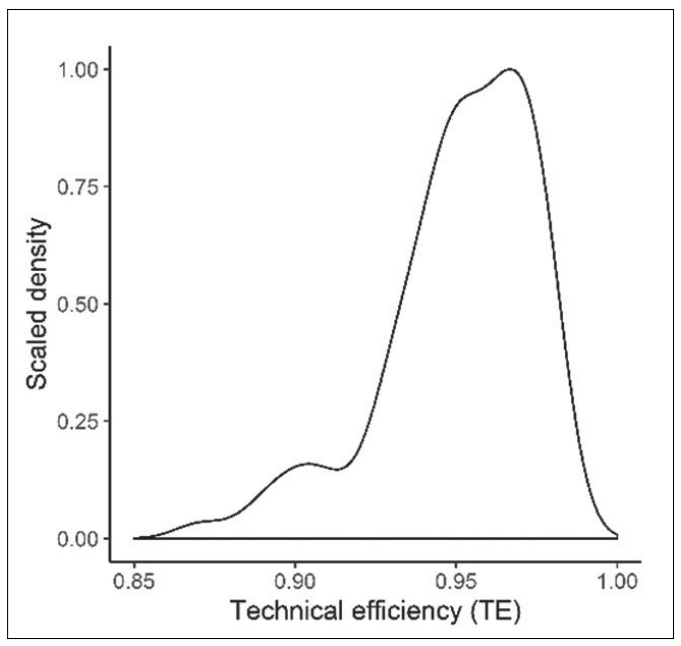

ber country would indicate that Kosovo's agriculture may be guided by the CAP program like all other EU countries, and the dairy sector may be ready to rise in line with CAP's expectations.

It is important to know how the increase in dairy production affects female and male farmers. For example, gender inequality incurs economic costs and missed opportunities for development (Daci, 2014). Considering the importance of female farmers in agriculture, we observe also as how efficient they are in producing milk. There are still more male than female Kosovar farmers receiving advising sessions for government farm grant applications (MAFRD, 2017). To mitigate some of these negative impacts in agriculture, it can be vital to promote dairy production equally among female and male farmers. Around $95 \%$ of the dairy farmers in the study's sample are male and roughly $5 \%$ are female. Figure 2 suggests that female dairy farmers from this sample have essentially the same mean TE of 0.95 as male dairy farmers despite the sample's small number of female farmers. Male farmers, nevertheless, have a slightly greater median efficiency score of 0.95 compared to female farmers $(0.94)$. To investigate further the underlying assumption, we conduct a t-test involving the efficiency scores of female and male farmers. We find that there is not a true difference in the efficiency means $(p$-value $=0.89)$ between the two farmer

Figure 2 - Technical efficiency scores by gender.

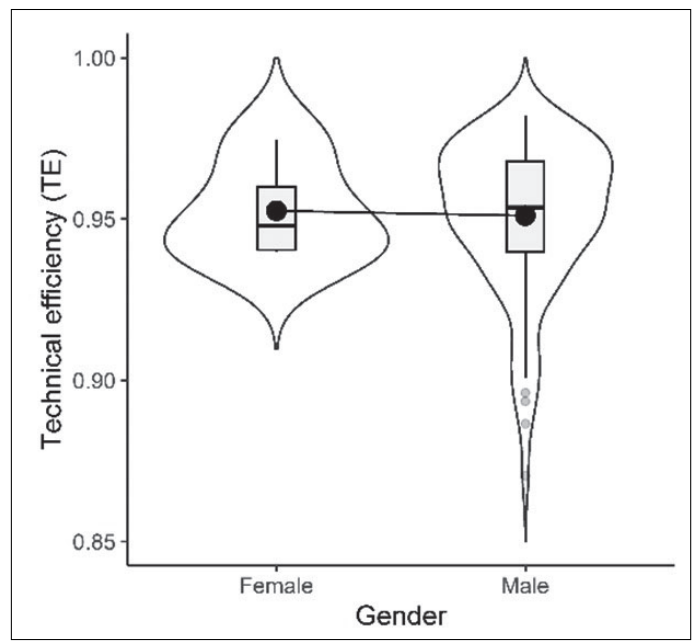


groups. Although there is an insignificant mean difference, yet the near parity by gender is encouraging. Kosovar female dairy farmers in our sample are able to achieve similar TE to male farmers in milk production.

\section{Conclusion}

Dairy farmers may search for ways to achieve production efficiency through considering the right levels of incurring concentrate feed and pre-production costs. Forage feed costs were only marginally significant. Nevertheless, incurring the right level of forage feed costs in the process of milk production remains still important. Another appealing observation is that concentrate feed costs are higher because the feed grains are mainly imported. The government of Kosovo recognizes that efficient milk production among commercially oriented farmers facilitates the development of the dairy industry. Little attention, however, has been given in the improvement and expansion of the irrigation systems. These can lead to yield and quality improvements of forage and grain feeds among the dairy farms. Other governmental contribution towards reducing concentrate feed costs while maintaining total milk production can be through investing more in developing the domestic concentrate feed subsector. These may help increase efficiency in milk production.

This study suggests that the inefficiency effects are significant in the Cobb-Douglas production function indicating that commercially oriented dairy farmers can improve more their technical efficiency. There is a small gap for improvement, although these farmers have the potential to become fully efficient in producing milk. The results of the study revealed an average of $95 \%$ of TE among Kosovar dairy farms. Both female and male farmers can only increase $\mathrm{TE}$ in milk production by $5 \%$ if prevailing inefficiencies are overcome without increasing the use of inputs. However, this study reveals an opportunity for Kosovo dairy farms still facing increasing returns to scale. Thus investments in physical and marketing infrastructure that facilitates continued growth in the size of dairy farms would be beneficial to this sector. These results can be helpful for policy makers when adopting policies to help dairy farms achieve complete efficiency. At a farm level, farmers may take interest in the evidence of the influence of feed and pre-production costs on the total milk production.

\section{Acknowledgments}

The authors thank the dairy farmers throughout Kosovo for their input in the gathering of the data.

\section{References}

Aigner D., Lovell K., Schmidt P., 1977. Formulation and estimation of stochastic frontier production function models. Journal of Econometrics, 6(1): 21-37.

Aktürk D., Bayramoğlu Z., Savran F., Tatlıdil F.F., 2010. The factors affecting milk production and milk production cost: Çanakkale case-Biga. Kafkas Üniversitesi Veteriner Fakültesi Dergisi, 16(2): 329-335.

Aneani F., Anchirinah V.M., Asamoah M., OwusuAnsah F., 2011. Analysis of economic efficiency in cocoa production in Ghana. African Journal of Food, Agriculture, Nutrition and Development, 11(1).

Bajrami E., Wailes E.J., Dixon B.L., Musliu A., Durand-Morat A., 2017. Factors affecting the technical efficiency of dairy farms in Kosovo. Journal of Central European Agriculture, 18(4): 823-840.

Battese G.E., Coelli T.J., 1995. A model for technical efficiency effects in a stochastic frontier production function for panel data. Empirical Economics, 20(1): 325-332.

Bogdanoviü V., Petroviü M.D., 2014. Features and possibilities for optimizing farm milk production in Serbia. Proceedings of the International Symposium on Animal Science, September 2014, Belgrade-Zemun.

Charnes A., Cooper W., Rhodes E., 1978. Measuring the efficiency of decision making units. European Journal of Operational Research, 2(6): 429-444.

Coelli T.J., Rao D.S.P., O'Donnell C.J., Battese G.E., 2005. An introduction to efficiency and productivity analysis. New York: Springer US, pp. 349.

Daci E., 2014. Gender perspective in agriculture value chain development in Kosovo. Turkish Journal of Agriculture and Natural Sciences, (2): 1996.

D’Amico M., Coppola A., Chinnici G., Di Vita G., Pappalardo G., 2013. Agricultural systems in the 
European Union: an analysis of regional differences. New Medit, 12(4): 28-34.

Kao C., Liu S.-T., 2000. Data envelopment analysis with missing data: an application to University libraries in Taiwan. Journal of the Operational Research Society, 51(8): 897-905.

Kumbhakar S.C., Lovell C.A.K., 2000. Stochastic frontier analysis. Cambridge (UK): Cambridge University Press, pp. 343.

Lyu S.L., White F.C., Lu Y-C., 1984. Estimating effects of agricultural research and extension expenditures on productivity: A translog production approach. Southern Journal of Agricultural Economics, 16(2): 1-8.

Meeusen W., van den Broeck J., 1977. Efficiency estimation from Cobb-Douglas production functions with composed error. International Economic Review, 18(2): 435-444.

Miftari I., Gjonbalaj M., Johnsen H.F., 2010. The estimation of Kosovo consumer expenditures for milk and dairy products: the role of demographic and socio-economic factors. In: University of IASI Faculty of Economics and Business Administration, The eco-economic challenges for XXI Century, Iasi, Romania, 5-6.

Ministry of Agriculture, Forestry and Rural Development - MAFRD, 2006. Agriculture and Rural Development Plan (ARDP) 2007-13, November 2006.

Ministry of Agriculture, Forestry and Rural Development - MAFRD, 2015. Green Report 2015, available at: http://www.mbpzhr-ks.net/repository/docs/Green_Report_Kosovo_2015_Eng_ final.pdf. Pristina, Kosovo.

Ministry of Agriculture, Forestry and Rural Development - MAFRD, 2017. Green Report 2017, available at: http://www.mbpzhr-ks.net/repository/docs/ Raporti_i_Gjelber_2017_Eng_Final.pdf. Pristina, Kosovo.

Musliu A., Bajrami E., Tsiboe F., Popp J.S., 2017. Evaluating the impact of the Value Added Tax reform on raw milk collection in Kosovo. New Medit, 16(1): 29-35.

Musliu A., Gjonbalaj M., Sherifi K., Meqe M., 2009. Economic losses related to raw milk quality on commercial daily farms in Kosovo. New Medit, 8(3): 49-53.

Musliu A., Sopi L., Wood M., Hamidi A., 2015. Development of the local broiler industry in Kosovo. Albanian Journal of Agricultural Sciences, 14(2): 121-126.

Pandurević T., Mojević M., Rankić I., Ristanović B., 2015. Analysis of some cattle farms focused on milk production. Acta Agriculturae Serbica, 40(20): 127-135.

Pilyavskyy A.I., Matsiv Y.I., Vovchak O.D., 2012. Cost efficiency of Ukrainian banks. Does it make difference? Wspótczesne Problemy Zarzadzania, 1/2012.

Reinhard S., Lovell C.K., Thijssen G.J., 2000. Environmental efficiency with multiple environmentally detrimental variables; estimated with SFA and DEA. European Journal of Operational Research, 121(2): 287-303.

Sauer J., Davidova S., Latruffe L., 2012. Determinants of smallholders' decisions to leave land fallow: The case of Kosovo. Journal of Agricultural Economics, 63(1): 119-141.

Scippacercola S., Sepe E., 2016. Critical comparison of the main methods for the technical efficiency. Electronic Journal of Applied Statistical Analysis, 9(4): 760-780.

Signorello G., Pappalardo G., 2003. Domestic animal biodiversity conservation: A case study of rural development plans in the European Union. Ecological Economics, 45 (3): 487-499.

Yuya B.A., Daba N.A., 2018. Rural households livelihood strategies and its impact on livelihood outcomes: The case of eastern Oromia, Ethiopia, AGRIS on-line Papers in Economics and Informatics, 10(2): 93-103.

Zhang P., Kang S., 2015. Cost efficiency of Chinese banks-Using stochastic frontier analysis. International Journal of Management and Applied Science, 11(1): 2394-7926.

Zuzaku A., 2014. Marketing research is path towards the development of agriculture in Kosovo. In: Economic and Social Development: Book of Proceedings; Varazdin Development and Entrepreneurship Agency, Varazdin, Croatia, pp. 488-496. 